\title{
CLINICAL DIAGNOSIS OF SUBSCAPULARIS TENDON TEAR USING THE BEAR HUG SEMIOLOGICAL MANEUVER
}

Márcio Schiefer ${ }^{1}$, Yonder Archanjo Ching-San Júnior², Sérgio Maurício Silva ${ }^{3}$, César Fontenelle ${ }^{4}$, Marcos Genúncio Dias Carvalho ${ }^{5}$, Fabio Garcia de Faria', José Sérgio Franco ${ }^{7}$

\section{ABSTRACT}

Objective: To evaluate the Bear Hug maneuver for clinically diagnosing subscapularis tendon tears, and compare this with other maneuvers described previously (Lift-off, Napoleon and Belly Press). Methods: Forty-nine patients with rotator cuff injuries who had undergone arthroscopy to repair the injury and had previously been assessed using the semiological maneuvers mentioned above were evaluated. Results: The diagnostic values obtained for the Bear Hug test were as follows: sensitivity $75 \%$, specificity $56 \%$, positive predictive value $62 \%$, negative predictive value $70 \%$ and accuracy $65 \%$. Conclusion: The highest sensitivity and negative predictive value values were obtained with the Bear Hug test. The highest specificity value was seen with the Lift-off test. The Belly press test gave the greatest specificity, positive predictive and accuracy values.

Keywords - Shoulder; Arthroscopy; Rotator Cuff; Tendon Injuries

\section{INTRODUCTION}

Rotator cuff injuries are an important cause of pain and functional incapacity of the shoulder ${ }^{(1,2)}$. With increasing life expectancy among the population and the popularization of modern diagnostic methods, partial and total lesions of the shoulder are becoming increasingly common ${ }^{(3)}$. Lesions of the subscapularis occur more frequently in association with lesions of the long portion of the biceps and/or lesions of the other tendons of the rotator cuff ${ }^{(4-6)}$. Lesions of the subscapularis alone are uncommon ${ }^{(1,7)}$.

Although the subscapularis is the largest muscle of the rotator cuff, with its tendon covering the entire anterior surface of the shoulder joint, isolated lesions of the subscapularis only occur in $2.1 \%$ to $10.5 \%$ of the patients with shoulder tendon injuries ${ }^{(1,3,8,9)}$. Because of the low reported incidence, little importance was given to lesions of the subscapularis in the scientific literature until 1991, when Gerber and Krushell(10) described a series of cases of isolated lesions of the subscapularis.

From then onwards, semiological maneuvers for diagnosing these lesions started to be described in the literature worldwide. Gerber and Krushell $(1991)^{(10)}$ described a test named lift-off and in 1996, Gerber et $a l^{(11)}$ described another test, known as belly press. In 2002, Burkhart and Tehrany ${ }^{(12)}$ defined the Napoleon test $^{(12)}$. However, none of these maneuvers presented satisfactory sensitivity and specificity, thus resulting in low positive predictive values.

In successive arthroscopy procedures, Barth et al ${ }^{(13)}$ observed that several lesions of the upper portion of the subscapularis tendon were not foreseen by the belly press and lift-off maneuvers, given that the uppermost

\footnotetext{
1 - Master's Student in the School of Medicine, Federal University of Rio de Janeiro (UFRJ); Orthopedist in the National Institute of Traumatology and Orthopedics (INTO), Rio de Janeiro, RJ, Brazil.

2 - Orthopedist; Trainee in the Shoulder and Elbow Group, National Institute of Traumatology and Orthopedics (INTO), Rio de Janeiro, RJ, Brazil.

3 - Resident Physician (R2) in Orthopedics and Traumatology at HUCFF, UFRJ.

4 - Head of Clinical Medicine and Coordinator of the Medical Residence Program, Orthopedics and Traumatology Clinic, HUCFF, UFRJ, Rio de Janeiro, RJ, Brazil.

5 - Orthopedist; Titular Member of the Brazilian Society of Orthopedics, São Paulo, SP, Brazil.

6 - Resident Physician (R3) in Orthopedics and Traumatology at HUCFF, UFRJ, Rio de Janeiro, RJ, Brazil.

7 - PhD. Associate Professor and Head of the Department of Orthopedics and Traumatology, UFRJ, Rio de Janeiro, RJ, Brazil.

Work performed in the in Orthopedics and Traumatology Clinic, HUCFF, UFRJ, Rio de Janeiro, RJ.

Correspondence: Av. Afrânio de Melo Franco 141/110, Leblon, 22430-060 Rio de Janeiro, RJ. E-mail: marcioschiefer@hotmail.com

Work received for publication: April 16, 2011; accepted for publication: January 10, 2012.
}

The authors declare that there was no conflict of interest in conducting this work 
fibers were only recruited in situations of internal rotation of the shoulder with the elbow in the most anterior position ${ }^{(13)}$. Searching for a maneuver with greater accuracy that would enable quantification of the lesion, Barth et al (2006) ${ }^{(13)}$ described the bear hug test. In this semiological maneuver, the patient is placed in an upright standing position. The hand ipsilateral to the affected shoulder is positioned on the contralateral shoulder with the fingers stretched out and elbow positioned anteriorly to the body. The patient is asked to maintain this position (resisted internal rotation) while the examiner tries to perform external rotation through applying a force to the patient's forearm so as to remove his hand from his shoulder (Figure 1). If the patient is unable to keep his hand on his shoulder, or the resistance is $20 \%$ less than that of the contralateral side, the test is considered to be positive. Force equivalent to that of the other side and absence of pain define the test as negative. The result is considered to be intermediate when the patient is able to resist the examiner's force, but says that it was painful to do so.

Our main objective was to evaluate the diagnostic capacity of the bear hug maneuver for lesions of the subscapularis, taking arthroscopic examination as the gold standard. The secondary objective of this study was to compare this maneuver with the tests described previously (lift-off, Napoleon and belly press)

\section{MATERIALS AND METHODS}

Between August 2008 and March 2009, all patients attended at the shoulder and elbow outpatient clinic with complaints of shoulder pain, with or without associated trauma, were examined by a physician who was a specialist in shoulder complaints (with more than 250 arthroscopic procedures performed and four years of experience). After taking the patient's history, a complete physical examination was performed on the shoulder, consisting of inspection, palpation and special tests. These included the belly press, lift-off, Napoleon and bear hug test, i.e. the subject of the present study. All of these tests assess lesions of the subscapularis tendon. In addition, tests to evaluate the integrity of the supraspinatus, infraspinatus and long head of the biceps were performed.

The bear hug maneuver was performed as described by Barth et $a l^{(13)}$ and its results were graded as explained in Table 1.

Magnetic resonance imaging examinations were

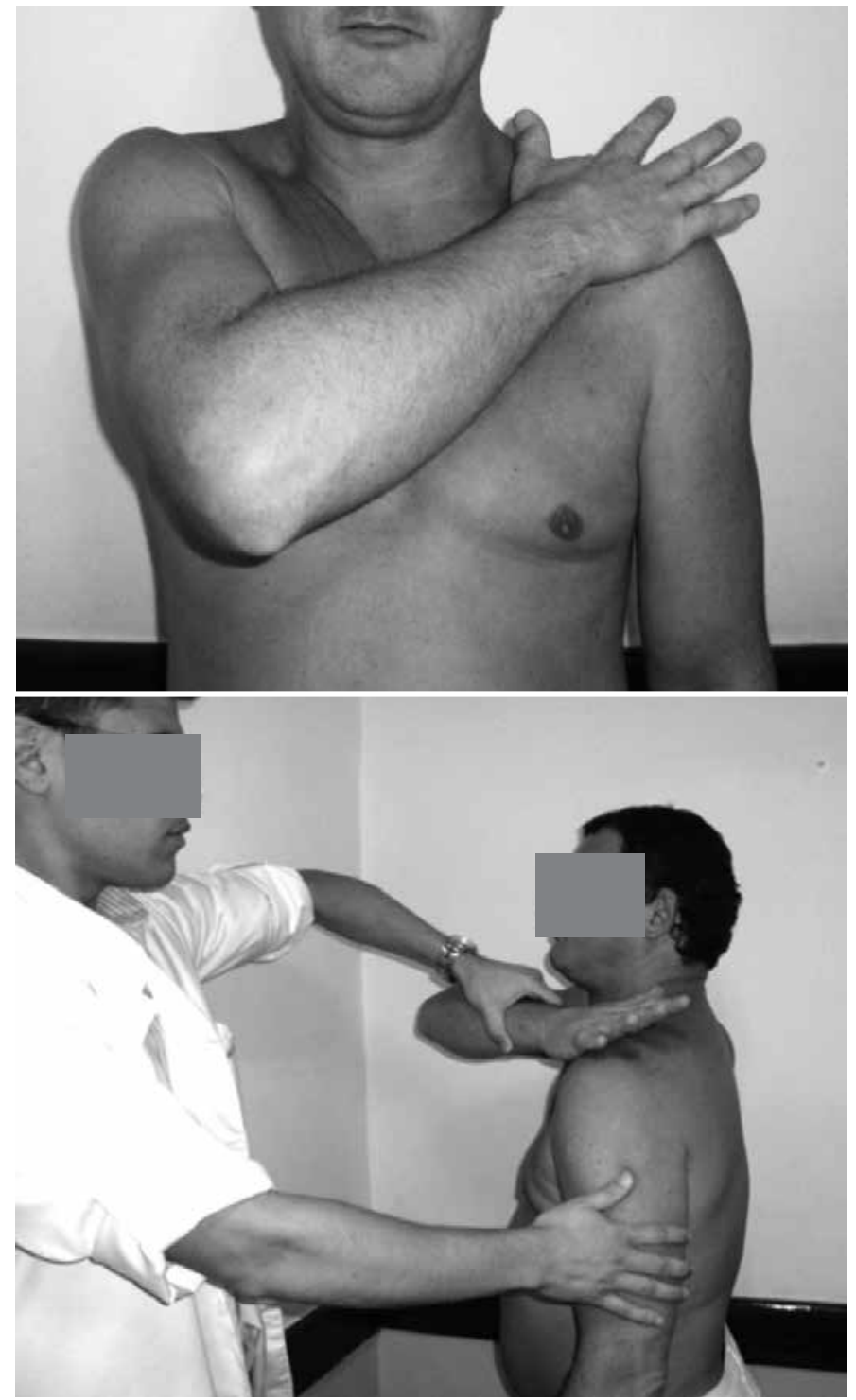

Figure 1 - Bear hug semiological maneuver as described by Barth et al ${ }^{(13)}$. The patient is placed in an upright standing position. The hand ipsilateral to the affected shoulder is positioned on the contralateral shoulder with the fingers stretched out and the elbow positioned anteriorly to the body. The patient is asked to maintain this position (resisted internal rotation) while the examiner tries to perform external rotation by applying a force on the forearm so as to remove the patient's hand from his shoulder. If the patient is unable to keep his hand on his shoulder, or the resistance is $20 \%$ lower than on the contralateral side, the test is considered to be positive. If the force is equivalent to that of the opposite side and pain is absent, the test is defined as negative.

Table 1 - Possible results from the bear hug maneuver.

\begin{tabular}{c|c}
\hline Type & Grading of the bear hug test \\
\hline 0 & Normal: absence of pain and grade 5 muscle strength \\
\hline 1 & Intermediate: pain and grade 5 muscle strength \\
\hline 2 & Positive: grade 4 muscle strength \\
\hline
\end{tabular}

performed on patients with suspected rotator cuff injuries. Patients with this diagnosis and with an indication for surgery underwent arthroscopic repair of the lesion. The surgical indication was pain, with or without associated diminution of muscle strength, in 
patients with complete lesions of one or more tendons of the rotator cuff. In cases of partial lesions, surgical treatment was performed if the symptoms persisted despite physiotherapeutic treatment lasting for at least six months. Patients with previous shoulder surgery or other pathological conditions that could result in pain, such as arthrosis, calcaneal tendinitis, instability or adhesive capsulitis were rejected from the study group. The arthroscopic surgery was performed with the patient in a semi-seated position (deckchair), under general anesthesia and brachial plexus blockade. During arthroscopy, the joint was inspected in accordance with the proposal of Snyder ${ }^{(14)}$, with special attention to the condition of the subscapularis. The tendons were evaluated using optic viewers of 30 and $70^{\circ}$ and the upper limb was left free for mobilization during the surgery. Adduction and internal rotation maneuvers were performed to facilitate viewing of the most lateral portion of the subscapularis, including its insertion in the lesser tubercle. All the data were noted down and all the arthroscopic procedures were recorded on DVD for documentation and revision when necessary.

From arthroscopy, the tendon of the subscapularis muscle was described as complete (inserted) or torn (ruptured). Torn subscapularis tendons were described as proposed by Lafosse et $a l^{(15)}$ (Table 2). In addition, the complete tendons that presented signs of tendinosis (fibrillation, narrowing or other degenerative structural alterations without affecting the insertion area) were classified separately. The results obtained from the physical examination were compared with the arthroscopic findings and the diagnostic values for lesions of the subscapularis tendon were calculated (complete and partial; Lafosse I to V).

The results were analyzed by a professional mathematician-statistician. In addition to calculating the diagnostic values for each test, the chi-square test was performed to evaluate the relationship of the subscapularis tendon lesion with the following variables: age, sex, dominance, presence of nighttime pain,

Table 2 - Classification of lesions of the subscapularis tendon according to Lafosse et al ${ }^{(15)}$.

\begin{tabular}{c|c}
\hline Type & Tendon \\
\hline I & Partial lesion of the upper third of the tendon \\
\hline II & Complete lesion of the upper third of the tendon \\
\hline III & Complete lesion of the upper two thirds of the tendon \\
\hline IV & Completely torn tendon \\
\hline V & $\begin{array}{c}\text { Irreparable complete lesion } \\
\text { (static anterosuperior subluxation) }\end{array}$ \\
\hline
\end{tabular}

presence of pain on exertion and history of shoulder trauma. The relationships of each of the semiological maneuvers performed were compared with each other by means of the Friedman test.

The diagnostic values for the bear hug maneuver were calculated in two different ways. Firstly, we only considered that results grade as 2 were positive. Secondly, we considered that rates graded 1 and 2 were positive (Table 1).

\section{RESULTS}

Forty-nine patients were included in this study, of whom 21 were male and 28 were female, with ages ranging from 23 to 83 years (mean of 51.12 years and median of 51 years). Forty-one of the patients reported pain in the dominant shoulder. All the patients had undergone classical physiotherapeutic treatment prior to surgery. Twenty-eight patients presented nighttime pain, 21 reported previous trauma and 41 reported worsening of the pain on exertion.

Among the 49 patients studied, 15 had a healthy tendon, 10 presented tendinosis and 24 had tendon lesions, of which 18 had partial lesions in the upper third (Lafosse I), four had complete lesions in the upper third (Lafosse II) and two had complete lesions encompassing the entire tendon, with or without retraction (Lafosse IV). Two patients who presented longitudinal lesions of the upper third, without deinsertion, were included in Lafosse type I. The prevalence of tendinosis of the subscapularis in this study was $20 \%$ and the prevalence of tendon lesions was $49 \%$. Out of the 49 patients studied, 21 (42.85\%) presented lesions resulting from previous trauma.

\section{Sensitivity}

Taking into consideration presence or absence of a lesion, the sensitivity calculated for the bear hug test was $75 \%$, while it was $25 \%$ for the lift-off test. The values for the Napoleon and belly press tests were respectively $41 \%$ and $45 \%$.

\section{Specificity}

Using the same criteria, we calculated the specificity for diagnosing the lesion, through comparison of the physical examination between patients with a complete tendon and those with a torn tendon. The results obtained were $56 \%$ for the bear hug test, $92 \%$ for the lift-off test, $80 \%$ for Napoleon and $92 \%$ for the belly press test. 


\section{Positive predictive value}

The positive predictive values (PPV) for the bear hug, lift-off, Napoleon and belly press tests with regard to diagnosing the lesion were respectively $62 \%$, $75 \%, 66 \%$ and $84 \%$.

\section{Negative predictive value}

With regard to diagnosing the lesion, the negative predictive values (NPV) calculated for the bear hug, lift-off, Napoleon and belly press tests were respectively $70 \%, 56 \%, 59 \%$ and $64 \%$.

\section{Accuracy}

The accuracy of the tests for diagnosing the lesion was $65 \%$ for the bear hug, $59 \%$ for the lift-off, $61 \%$ for Napoleon and $69 \%$ for the belly press.

The diagnostic values listed above are shown in Table 3. It is worth emphasizing that these values were obtained by taking both the tests in which the patient presented weakness (muscle strength grade 4) and the tests in which the patient presented pain (but with strength preserved) to be positive. When we considered only the cases of weakness as positive (and the cases with pain but without weakness as negative), we obtained the values shown in Table 3. The results from the four tests performed are presented in Table 4.

The relationship shown by the subscapularis tendon lesion with the following variables was analyzed statistically: age, sex, dominance, presence of nighttime pain, presence of pain on exertion and history of shoulder trauma. Only dominance $(p=0.04)$ and occurrence of trauma $(p=0.0025)$ were related to the presence of lesions in the subscapularis. There was a

Table 3 - Evaluation of the bear hug semiological test, taking pain and weakness as positive (results $1+2$ ) or weakness alone as positive (result 2). The sensitivity, specificity, positive predictive value, negative predictive value and accuracy were calculated.

\begin{tabular}{c|c|c}
\hline & $\begin{array}{c}\text { Bear hug } \\
\text { (pain and weakness) }\end{array}$ & $\begin{array}{c}\text { Bear hug } \\
\text { (weakness alone) }\end{array}$ \\
\hline Sen (\%) & 75 & 12,5 \\
\hline Spec (\%) & 56 & 92 \\
\hline PPV (\%) & 62 & 60 \\
\hline NPV (\%) & 70 & 52 \\
\hline Accuracy (\%) & 65 & 53 \\
\hline \multicolumn{2}{|c}{ Sen: sensitivity; Spec: specificity; PPV: positive predictive value; NPV: negative predictive value. }
\end{tabular}

Table 4 - Evaluation of the bear hug, lift-off (Gerber), Napoleon and belly press semiological tests for diagnosing lesions (partial or total) of the subscapularis tendon.

\begin{tabular}{c|c|c|c|c|c}
\hline & SEN (\%) & SPEC (\%) & PPV (\%) & NPV (\%) & ACCURACY (\%) \\
\hline Bear Hug & 75 & 56 & 62 & 70 & 65 \\
\hline Belly Press & 45 & 92 & 84 & 64 & 67 \\
\hline Napoleão & 41 & 80 & 66 & 59 & 61 \\
\hline Gerber & 25 & 92 & 75 & 56 & 59 \\
\hline \\
Sen: sensitivity; Spec: specificity; PPV: positive predictive value; NPV: negative predictive value.
\end{tabular}

relationship between positive results in the belly press test and occurrence of trauma $(p=0.0096)$. When compared between each other, the results from the semiological maneuvers showed different behavior in the group of patients studied $(p<0.00001)$.

\section{DISCUSSION}

The prevalence of lesions of the subscapularis in this study was $49 \%$, which was significantly greater than the prevalence found in the original description by Barth et $a l^{(13)}(29.4 \%)$. This can be explained by the exclusion criteria used in the present study. We only evaluated patients who underwent arthroscopy to repair rotator cuff injuries, while in the group of patients in the original study, patients who underwent arthroscopy due to other pathological conditions were also included. In analyzing only the patients with rotator cuff injuries, Barth et $a l^{(13)}$ found a prevalence of $58.8 \%$. In another study, Bennett ${ }^{(16)}$ demonstrated a prevalence of subscapularis lesions of $27 \%$ in the population studied, while Sakurai et $a l^{(17)}$ found a prevalence of $37 \%$ in a study on cadavers. The prevalence of subscapularis lesions in the present study was identical to what was found by Lafosse et $a l^{(15)}$. The mean age of the patients in this study was similar to what was found in other series ${ }^{(3,4,6,15,18)}$.

In the description of the bear hug maneuver by Barth et $a l^{(13)}$, the sensitivity was $60 \%$, specificity 91.7\%, PPV 75\% and NPV 84.6\%. In Gerber's lift-off test, the sensitivity was $17.6 \%$, specificity $100 \%$, PPV 100\% and NPV 76.7\%. The Napoleon test had sensitivity of $25 \%$, specificity $97.9 \%$, PPV $83.3 \%$ and NPV $75.8 \%$. The evaluation of the belly press maneuver furnished sensitivity of $40 \%$, specificity of 97.9\%, PPV 88.9\% and NPV 79.7\%.

In our study, we obtained higher sensitivity $(75 \%)$, but lower specificity (56\%), PPV (62\%), NPV (70\%) and accuracy (65\%) (Table 5). The discrepancy may be explained by the different criteria used for considering the test to be positive, given that as observed earlier, Barth et $a l^{(13)}$ only considered patients to be positive if they presented diminished muscle strength (grade 4), while we also considered patients presenting pain in the tests to be positive. Nevertheless, even when we separately assessed the patients with diminished muscle strength as positive, we observed an even larger difference in relation to the values obtained by Barth et $a l^{(13)}$, except for specificity. 
Table 5 - Comparison between the results obtained in the present study and those achieved in the original study by Barth et $\mathrm{al}^{(13)}$.

\begin{tabular}{c|c|c}
\hline & Present study & Barth et al $^{(\mathbf{1 3 )}, \mathbf{2 0 0 6}}$ \\
\hline Sensitivity (\%) & 75 & 60 \\
\hline Specificity (\%) & 56 & 92 \\
\hline PPV (\%) & 62 & 75 \\
\hline NPV (\%) & 70 & 84 \\
\hline Accuracy (\%) & 65 & 82 \\
\hline
\end{tabular}

PPV: positive predictive value; NPV: negative predictive value.

The discrepancy between the results from the two studies can be attributed to the difference in lesion prevalence, coming from different sample selection criteria. In other words, the populations studied were different.

In the present study, we observed that except for specificity, the diagnostic values of the bear hug test were higher when we took the tests with strength deficits and those with painful findings both to be positive. Twenty-four patients presented pain in the tests, with normal muscle strength. Of these, nine did not have lesions of the subscapularis (although seven presented tendinosis), 12 had partial lesions in the upper third (Lafosse I), two had complete lesions in the upper third (Lafosse II) and one had a complete lesion of the entire tendon (Lafosse IV). Therefore, out of all the patients with painful tests, only two presented normal tendons and thus we deemed it to be appropriate to also include these cases as positive test results.

Out of the 11 patients with false-positive bear hug tests, six had lesions of the supraspinatus and one a lesion of the long portion of the biceps. According to Barth et $a l^{(13)}$, the length of the supraspinatus explains the presence of pain in this group, due to recruitment of the fibers of the supraspinatus during anterior elevation of the shoulder, which does not occur in the

\section{REFERÊNCIAS}

1. Arai R, Sugaya H, Mochizuki T, Nimura A, Moriishi J, Akita K. Subscapularis tendon tear: an anatomic and clinical investigation. Arthroscopy. 2008;24(9):997-1004.

2. Lyons RP, Green A. Subscapularis tendon tears. J Am Acad Orthop Surg. 2005;13(5):353-63.

3. Flury MP, John M, Goldhahn J, Schwyzer HK, Simmen BR. Rupture of the subscapularis tendon (isolated or in combination with supraspinatus tear): when is a repair indicated? J Shoulder Elbow Surg. 2006;15(6):659-64.

4. Kim SH, Oh I, Park JS, Shin SK, Jeong WK. Intra-articular repair of na isolated partial articular-surface tear of the subscapularis tendon. Am J Sports Med. 2005;33(12):1825-30.

5. Bergin D, Parker L, Zoga A, Morrison W. Abnormalities on MRI of the subscapularis tendon in the presence of a full-thickness supraspinatus tendon tear. AJR Am J Roentgenol. 2006;186(2):454-9.

6. Checchia SL, Miyazaki AN, Fregoneze M, Santos PD, Silva LA, Ortiz RT, Kusabara FI, Santos TBC. Lesão isolada do tendão do subescapular. Acta Ortop Bras. 2009;17(1):26-30.

7. Tung GA, Yoo DC, Levine SM, Brody JM, Green A. Subscapularis tendon tear: primary and associated signs on MRI. J Comput Assist Tomogr. 2001;25(3):417-24.

8. Kreuz PC, Remiger A, Erggelet C, Hinterwimmer S, Niemeyer P, Gächter A. Isolated and combined tears of the subscapularis tendon. Am J Sports Med. 2005;33(12):1831-7.

9. Li XX, Schweitzer ME, Bifano JA, Lerman J, Manton GL, El-Noueam KI. MR other tests. Tendinopathy of the biceps may also cause pain in the position in which the test is performed.

Comparative statistical analysis between the maneuvers studied revealed that they behaved differently among the patients evaluated. In our study, the highest values for sensitivity and NPV were obtained with the bear hug. The highest values for specificity were found in the lift-off and belly press tests. The latter also furnished the highest PPV and accuracy. We therefore consider that using these maneuvers together is very useful in making clinical diagnoses of lesions of the subscapularis, since each test has its particular characteristics and the information from the tests complement each other. This was also observed by Lafosse et $a l^{(15)}$.

Some limitations of the present study should be noted. The sample population studied was relatively small, especially when considering only complete lesions of the subscapularis tendon. Most of the lesions were partial, which may make the clinical diagnosis more difficult. However, we decided to include partial lesions in the study because these occur frequently, are generally underdiagnosed and cause pain and diminished internal rotation strength ${ }^{(4)}$.

\section{CONCLUSION}

In the present study, the highest sensitivity and NPV were obtained from the bear hug (75 and 70\%, respectively). The highest specificity was found in the lift-off and belly press tests (92\%). The belly press test also furnished the highest accuracy and PPV (69\% and $84 \%$, respectively). evaluation of subscapularis tears. J Comput Assist Tomogr. 1999;23(5):713-7. 10. Gerber C, Krushell RJ. Isolated rupture of the tendon of the subscapularis muscle. Clinical features in 16 cases. J Bone Joint Surg Br. 1991;73(3):389-94.

11. Gerber $C$, Hersche $O$, Farron $A$. Isolated rupture of the subscapularis tendon. J Bone Joint Surg Am. 1996;78(7):1015-23.

12. Burkhart SS, Tehrany AM. Arthroscopic subscapularis tendon repair: Technique and preliminary results. Arthroscopy. 2002;18(5):454-63.

13. Barth JR, Burkhart SS, De Beer JF. The bear-hug test: a new and sensitive test for diagnosing a subscapularis tear. Arthroscopy. 2006;22(10):1076-84.

14. Snyder SJ. Shoulder Arthroscopy. California: Lippincott Williams \& Wilkins; 2006.

15. Lafosse L, Jost B, Reiland Y, Audebert S, Toussaint B, Gobezie R. Structural integrity and clinical outcomes after arthroscopic repair of isolated subscapularis tears. J Bone Joint Surg Am. 2007;89(6):1184-93.

16. Bennett WF. Subscapularis, medial, and lateral head coracohumeral ligament insertion anatomy. Arthroscopic appearance and incidence of "hidden" rotator interval lesions. Arthroscopy. 2001;17(2):173-80.

17. Sakurai G, Ozaki J, Tomita Y, Kondo T, Tamai S. Incomplete tears of the subscapularis tendon associated with tears of the supraspinatus tendon: cadaveric and clinical studies. J Shoulder Elbow Surg. 1998;7(5):510-5.

18. Edwards TB, Walch G, Sirveaux F, Molé D, Nové-Josserand L, Boulahia A, et al. Repair of tears of the subscapularis. J Bone Joint Surg Am. 2005;87(4):725-30. 